\title{
UTILIZAÇÃO DA PROGRESSÃO ARITMÉTICA DO COEFICIENTE DE CORRELAÇÃO DE PEARSON PARA PREVISÃO DA DESCARACTERIZAÇÃO SUPERFICIAL DE ROCHAS ORNAMENTAIS
}

\author{
USE OF ARITHMETIC PROGRESSION OF THE PEARSON CORRELATION COEFFICIENT \\ FOR PREDICTION OF SURFACE DISTORTION OF ORNAMENTAL ROCKS
}

\author{
Thiago M. BOLONINI'; Antonio M. GODOY ${ }^{2}$; Carlos Alberto M. FIGUEIREDO ${ }^{3}$; \\ António MAURÍCIO ${ }^{3}$; Manuel F. PEREIRA ${ }^{3}$ \\ ${ }^{1}$ Universidade Federal do Espirito Santo. Centro de Ciências Jurídicas Econômicas, Depto de Gemologia. End.: Av. Fernando \\ Ferrari, 514 - Goiabeiras, Vitória - ES. E-mail: thiago.bolonini@ufes.br \\ ${ }^{2}$ Universidade Estadual Paulista, Av. 24A, 1.515. Rio Claro-SP, Brasil. E-mail: mgodoy@rc.unesp.br \\ ${ }^{3}$ Centro de Petrologia e Geoquímica do Instituto Superior Técnico - IST, Av. Rovisco Pais no ${ }^{\circ}$. Lisboa, Portugal. \\ E-mails: carlos.m.figueiredo@ist.utl.pt,pcd2045@ist.utl.pt, mfcp@ist.utl.pt \\ Introdução \\ Contexto Geológico Regional \\ Materiais e Métodos \\ Resultados e Discussão \\ Conclusões \\ Agradecimentos \\ Referências
}

\begin{abstract}
RESUMO - No envelhecimento acelerado de rochas ornamentais em câmara saturada em $\mathrm{SO}_{2}$, as interações físico-químicas têm o objetivo de simular a exposição das mesmas às chuvas ácidas. As presenças de $\mathrm{SO}_{2}$, de $_{2} \mathrm{O}$, somadas à incidência de radiação solar (externa) permitem a formação fotoquímica do ácido sulfúrico $\left(\mathrm{H}_{2} \mathrm{SO}_{4}\right)$ e a correlação entre as digitalizações das superfícies dos corpos de prova, antes e após as exposições ao $\mathrm{H}_{2} \mathrm{SO}_{4}$, propicia a análise da evolução das alterações causadas. A estimativa do tempo gasto, em anos, para que as alterações descaracterizem totalmente a aparência estética da superfície das amostras é feita com a progressão aritmética do coeficiente de correlação linear de Pearson ( $r$ ) que permite, quando igual a 0 (zero), afirmar a inexistência de correlação entre imagens de amostras submetidas ao ensaio e suas imagens originais ao natural. Os resultados apontam o Butterfly Gold como o mais susceptível à descaracterização estética superficial (3,08 anos), seguido do Butterfly Green (3,91 anos) e do Butterfly Beige (16,03 anos). Ressalta-se que a descaracterização não implica, necessariamente, em alteração ou comprometimento estrutural ou físicomecânico da rocha. A concentração do gás na câmara $(25 \mathrm{ppm})$ foi superelevada propositalmente para acelerar o processo de deterioração. É importante lembrar que a câmara simula as condições climáticas em fluxo praticamente contínuo necessitando o pesquisador, para as interpretações, considerar a concentração de $\mathrm{SO}_{2}$ na atmosfera, a duração das estações chuvosas, a incidência de chuvas ácidas e suas intensidades ao longo de um ano nos diferentes territórios. As previsões aqui realizadas não são impeditivos para aplicação destes materiais em ambientes externos nem tampouco internos, pois procedimentos usuais de limpeza podem ser perfeitamente aplicados para conservação dos mesmos.

Palavras-chave: Envelhecimento acelerado, descaracterização estética, correlação de imagens, coeficiente de correlação linear de Pearson, progressão aritmética.
\end{abstract}

ABSTRACT - In accelerated aging of dimension stones in $\mathrm{SO}_{2}$ saturated chamber, the physico-chemical interactions has the purpose of
simulate its exposure to acid rain. The presence of $\mathrm{SO}_{2}, \mathrm{H}_{2} \mathrm{O}$, added to incident solar radiation (external) allow the photochemical formation
of sulfuric acid $\left(\mathrm{H}_{2} \mathrm{SO}_{4}\right)$ and the correlation between $\mathrm{scanned}$ surfaces of the specimens, before and after the exposure to $\mathrm{H}_{2} \mathrm{SO}_{4}$, provides
the analysis of the alterations evolution. The estimated time spent, in years, for the changes to promote overall aesthetic distortion of the
sample surface appearance is done through the arithmetic progression of the Pearson's linear correlation coefficient $(r)$ allowing, when
equal to 0 (zero), assert the lack of correlation between images of samples subjected to the test and your original images. The results
indicate the Butterfly Gold as the most susceptible to superficial aesthetic decharacterization ( 3,08 years), followed by the Butterfly Green
(3,91 years) and Butterfly Beige ( 16,03 years). We emphasize that the decharacterization not necessarily imply in structural or physical-
mechanical impairment. The concentration of the gas in the chamber ( 25 ppm) was intentionally elevated to accelerate the deterioration
process. Remember that the camera simulates weather conditions practically in continuous flow requiring the researcher to the
interpretations consider the $\mathrm{SO}_{2}$ concentration at the atmosphere, the duration of the rainy seasons, the incidence of acid rain and its
intensity over a year in different territories. The estimates calculated do not prevent the application of these materials as external or internal
coatings as usual cleaning procedures can be seamlessly applied to conservation. Keywords: Accelerated aging, aesthetic decharacterization, correlation of images, Pearson's linear correlation coefficient, arithmetic progression.

\section{INTRODUÇÃO}

As rochas ornamentais selecionadas para de Itaperuna, município de Barra de São realização do presente estudo denominadas Francisco-ES, Brasil, e encontram-se descritos comercialmente como Butterfly Beige, Butterfly detalhadamente em Bolonini (2015), Bolonini \& Gold e Butterfly Green, são extraídas no distrito Godoy (2017), Bolonini et al. (2017). 
Especialistas em rochas ornamentais utilizam imagens, em diversas escalas, como ferramentas para quantificar alterações causadas por fenômenos físicos e/ou químicos decorrentes de intempéries (Figueiredo et al., 2005; Vazquez, 2011; Torquato et al., 2008), para auxiliar na visualização dos resultados de suas análises (Motoki et al., 1999) e para especificação desses materiais rochosos (Aires-Barros et al., 1991a, 1991b, 1991c; Motoki et al., 2006a, 2006b; Gokay \& Gundogdu, 2008; Figueiredo et al., 2004).

No que tange a alterabilidade, um dos grandes desafios enfrentados é estimar o tempo necessário para que a superfície de uma determinada rocha (polida ou não) seja totalmente descaracterizada, ou seja, para que ela perca a relação que tinha com sua aparência estética original.

Este trabalho busca auxiliar, com o uso de imagens, na previsão das descaracterizações estéticas superficiais dos litotipos comercialmente conhecidos como Butterfly Beige, Butterfly Gold e Butterfly Green, frente ao envelhecimento acelerado em câmara com atmosfera saturada em $\mathrm{SO}_{2}$, com base no coeficiente de correlação linear de Pearson e em progressões aritméticas do mesmo.

No ensaio de envelhecimento acelerado as interações físico-químicas entre temperatura, umidade, presença de $\mathrm{SO}_{2}$ e as rochas, tem o objetivo de simular sua exposição às chuvas ácidas.

$\mathrm{Na}$ câmara a presença de $\mathrm{SO}_{2}$, de $\mathrm{H}_{2} \mathrm{O}$ e a incidência de radiação solar (externa) permitem a formação fotoquímica (Sethi, 1971; McGraw, 1982) do ácido sulfúrico $\left(\mathrm{H}_{2} \mathrm{SO}_{4}\right)$ presente nas chuvas ácidas e a correlação entre as digitalizações das superfícies dos corpos de prova, antes e após as exposições, propicia a análise virtual da evolução das alterações causadas.

\section{CONTEXTO GEOLÓGICO REGIONAL}

As rochas estudadas são extraídas no distrito de Itaperuna, Município de Barra de São Francisco, Estado do Espírito Santo, Brasil, em um maciço rochoso intrusivo de alongado com aproximadamente $35 \mathrm{~km}$ de eixo maior de direção NE-SW (Figura 1).

Este corpo intrusivo insere-se no contexto do Orógeno Araçuaí (Pedrosa-Soares et al., 1992,
2001, 2006, 2007; Martins et al., 2004; Marshak et al., 2006; Alkimin et al., 2007; Noce et al., 2007) que, segundo texto publicado pela CPRM (2007) integraria a Suíte G5, de idade cambriana, possivelmente equivalente a Suíte Intrusiva Aimorés de natureza charnockitoide descrita por Pedrosa-Soares et al. (2007) no âmbito da folha geológica de Mantena-MG.

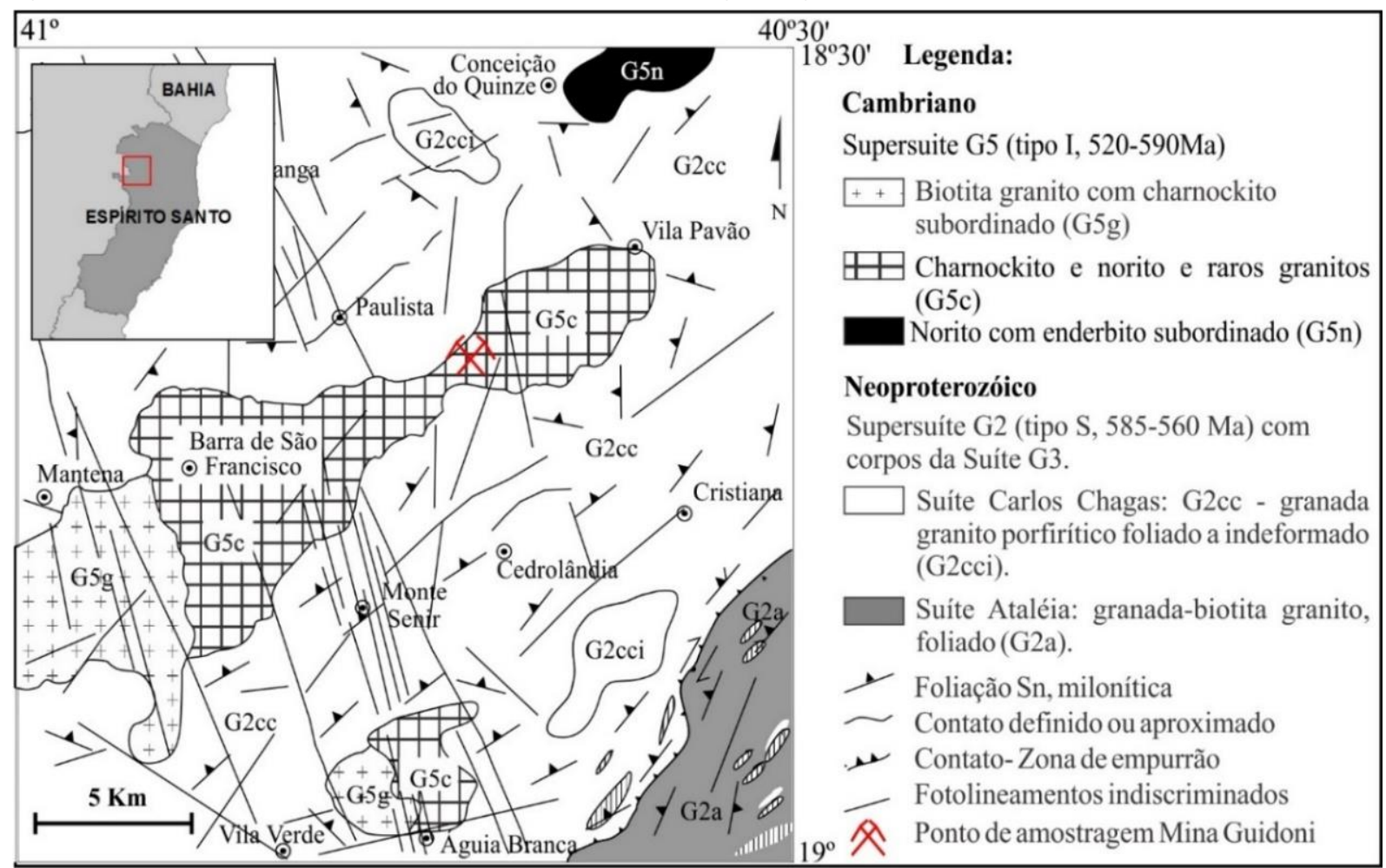

Figura 1 - Mapa geológico, adaptado, da folha Mantena-MG. (Modificado de Pedrosa-Soares et al., 2006). 
A suíte G5, de maneira geral, é constituída de intrusões graníticas do Tipo I, livres da foliação regional, cuja ocorrência se limita ao núcleo do orógeno. Estas intrusões podem conter fácies charnockíticas e enderbíticas. Na porção sul do orógeno, em decorrência da exposição de nível crustal mais profundo, são comuns plútons zonados que mostram núcleos (raízes) de composição básica. A composição predominante das intrusões G5 varia de monzogranito a sienogranito, geralmente porfirítico, com frequentes enclaves máficos e eventuais xenólitos de rocha encaixante (Almeida, 2004).

Roncato Júnior (2009), entretanto, coloca o Orógeno Araçuaí subdivido, na região da folha geológica de Mantena-MG, entre a Cambriana Suíte Intrusiva Aimorés (Charnockito) e a neoproterozoica Suíte Carlos Chagas (deformada). Tais subdivisões classificam de forma particular o mesmo conjunto de rochas.

\section{RESULTADOS E DISCUSSÃO}

As rochas ornamentais submetidas aos testes de envelhecimento acelerado em câmara com atmosfera saturada em dióxido de enxofre, denominadas comercialmente como Butterfly Beige, Butterfly Gold e Butterfly Green são extraídas em uma mesma pedreira e correspondem a variedades de quartzo sienitos com hiperstênio de color bege e verde, respectivamente (Figura 2).

Tratam-se de rochas com aspectos petrográficos e mineralógicos bastante similares, diferenciando-se principalmente pelas colorações exibidas. Descrições detalhadas destes litotipos encontram-se em Bolonini (2015), Bolonini \& Godoy, (2017) e Bolonini et al. (2017).

O Butterfly Beige (Figura 2A) corresponde a um quartzo-sienito com hiperstênio, com textura fanerítica inequigranular, hipidiomórfica, de granulação grossa a porfirítica com cristais que variam de $0,2 \mathrm{~cm}$ a $4,5 \mathrm{~cm}$, de coloração bege, estrutura isotrópica, composto por microclínio (62\%), plagioclásio (22\%), quartzo (11\%), granada (3\%), biotita e hiperstênio (2\%).

O Butterfly Gold (Figura 2B) corresponde a um quartzo-sienito com hiperstênio, rocha com textura fanerítica inequigranular, hipidiomórfica, com granulação grossa a porfirítica com cristais que variam de $0,2 \mathrm{~cm}$ a $4,5 \mathrm{~cm}$, de coloração marrom/ dourada (ferruginosa), estrutura isotrópica, composta por microclínio (58\%), plagioclásio (20\%), quartzo (16\%), granada (3\%), biotita e hiperstênio (3\%).

O Butterfly Green (Figura 2C), também corresponde um quartzo-sienito com hiperstênio, rocha alotriomórfica, com textura fanerítica inequigranular, com granulação grossa a porfirítica com cristais que variam de $0,2 \mathrm{~cm}$ a $4 \mathrm{~cm}$, de coloração verde, estrutura isotrópica, composta por microclínio (58\%), plagioclásio (20\%), quartzo (13\%), granada (6\%), biotita e hiperstênio (3\%).

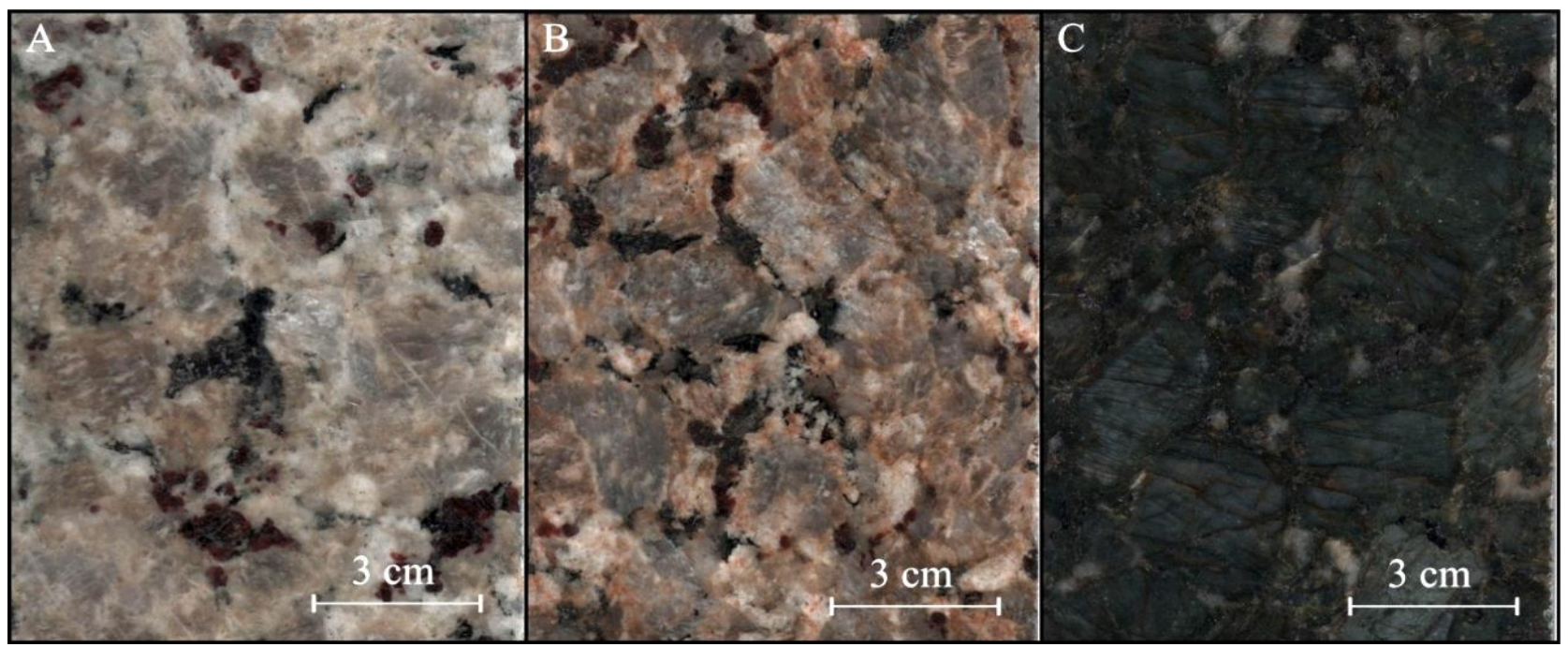

Figura 2 - Fotografias dos litotipos utilizados.

Legenda: A) Butterfly Beige; B ) Butterfly Gold; C) Butterfly Green.

As dimensões e as quantidades de corpos de prova utilizados para cada amostra (litotipo) estão relacionadas na tabela 1.
A câmara climática utilizada foi uma Fitoclima 300EDTU Aralab, configurada (Tabela 2) para passar por períodos intercalados 
de 7 horas com temperatura interna de $60^{\circ} \mathrm{C}$ e $30 \%$ de umidade (seguimentos 4 e 5) e 6 horas com $25^{\circ} \mathrm{C}$ e $95 \%$ de umidade (seguimento 6), com concentração de gás $\left(\mathrm{SO}_{2}\right)$ em 25 ppm.

Os períodos supracitados equivalem, somados, ao tempo diário médio de insolação a que as rochas são submetidas (das 5:30h às 18:30h e.g.) e o tempo excedente (seguimentos 1 ,
2, 5 e 7) é o que a câmara gasta para ligar e se estabilizar nas configurações de temperatura e umidade.

A câmara foi programada para realizar períodos ininterruptos de 25 ciclos, com avaliações visuais entre as exposições. A relação de todos os procedimentos adotados pode ser visualizada na tabela 3 .

Tabela 1 - Quantidades e dimensões dos corpos de prova utilizados para o ensaio.

\begin{tabular}{|c|c|c|c|c|c|c|c|c|}
\hline \multirow{2}{*}{ Amostras } & \multicolumn{2}{|c|}{ Quantidades } & \multicolumn{5}{|c|}{ Ciclos } & \multirow{2}{*}{ Forma e dimensões (cm) } \\
\hline & Individual & Total & $\mathbf{0}$ & 25 & 50 & 75 & 100 & \\
\hline Butterfly Beige & 5 & \multirow{3}{*}{15} & \multirow{3}{*}{\multicolumn{5}{|c|}{$\begin{array}{l}\text { Os corpos de prova utilizados foram os } \\
\text { mesmos para todos os ciclos }\end{array}$}} & \multirow{3}{*}{ Paralelepípedos de 10 x 15 × 02} \\
\hline Butterfly Gold & 5 & & & & & & & \\
\hline Butterfly Green & 5 & & & & & & & \\
\hline
\end{tabular}

Tabela 2 - Configuração do teste de envelhecimento acelerado.

\begin{tabular}{c|c|c|c|c|c|c|c}
\hline \multirow{2}{*}{ Propriedade } & \multicolumn{9}{c}{ Um ciclo* (segmentos) } \\
\cline { 2 - 10 } & $\mathbf{1}$ & $\mathbf{2}$ & $\mathbf{3}$ & $\mathbf{4}$ & $\mathbf{5}$ & $\mathbf{6}$ & $\mathbf{0 7} * *$ \\
\hline Temperatura $\left({ }^{\circ} \mathbf{C}\right)$ & 25 & 25 & 60 & 60 & 25 & 25 & 25 \\
\hline Umidade (\%) & 95 & 95 & 30 & 30 & 95 & 95 & 95 \\
\hline Tempo (h) & 0 & 1 & 1 & 6 & $1 \mathrm{~h} \mathrm{30min.}$ & 6 & $1 \mathrm{~min}$ \\
\hline Segmento seguinte & 2 & 3 & 4 & 5 & 6 & 3 & 7 \\
\hline
\end{tabular}

Notas: *Depois do $6^{\circ}$ segmento, o programa retorna automaticamente para os segmentos de 3 a 6 , por 24 vezes, antes de ir para o $7^{\circ}$ e último segmento; ** Este segmento só irá rodar depois de completados todos os outros ciclos $\left(3^{\circ}\right.$ ao $6^{\mathrm{o}}$ segmento), ou seja, no $25^{\circ}$ ciclo.

Tabela 3 - Etapas e procedimentos adotados para realização dos trabalhos.

\begin{tabular}{|c|c|c|c|c|}
\hline Ciclos & $\begin{array}{c}\text { Etapa 1 } \\
\text { (Laboratório) }\end{array}$ & $\begin{array}{c}\text { Etapa } 2 \\
\text { Pré-processamento (Corel } \\
\text { Draw X6) }\end{array}$ & $\begin{array}{c}\text { Etapa } 3 \\
\text { Correlação } \\
\text { (ImageJ) }\end{array}$ & $\begin{array}{c}\text { Etapa } 4 \\
\text { (Cálculos: Excel 2007) }\end{array}$ \\
\hline $\begin{array}{c}0 \\
\text { (Natural) }\end{array}$ & $\begin{array}{c}\text { Analise macroscópica } \\
\text { preliminar; } \\
\text { Digitalização (TIFF, } R G B \\
\text { 24bits, } 600 \text { dpi); } \\
\text { Analise visual (lupa } \\
\text { binocular óptica); } \\
\text { Inserção da câmara. }\end{array}$ & $\begin{array}{c}\text { Sobreposição; } \\
\text { Ajuste de rotação; } \\
\text { Recorte }(9 x 14 \mathrm{~cm}) \\
\text { Conversão: } T I F F / J P E G \text { e } \\
R G B \text { 24bits/ Escala de cinza } \\
\text { 8bits. }\end{array}$ & $\begin{array}{l}\text { Correlação } \\
\text { de imagens: } \\
\text { Natural- } \\
\text { Natural }\end{array}$ & $\begin{array}{l}\text { Coeficiente de correlação } \\
\text { linear de Pearson }(=1 \\
\text { correlação perfeita); } \\
\text { Progressão aritmética para } \\
\text { a total descaracterização e; } \\
\text { Tempo em anos. }\end{array}$ \\
\hline 25 & $\begin{array}{l}\text { Analise macroscópica; } \\
\text { inserção da câmara. }\end{array}$ & - & - & - \\
\hline 50 & $\begin{array}{c}\text { Analise macroscópica; } \\
\text { Digitalização (TIFF, RGB } \\
\text { 24bits, } 600 \text { dpi); } \\
\text { Análise visual (lupa } \\
\text { binocular óptica); } \\
\text { Inserção da câmara. }\end{array}$ & $\begin{array}{c}\text { Sobreposição; Ajuste de } \\
\text { rotação; } \\
\text { Recorte }(9 \times 14 \mathrm{~cm}) \\
\text { Conversão: } T I F F / J P E G \text { e } \\
\text { RGB 24bits/ Escala de cinza } \\
\text { 8bits. }\end{array}$ & $\begin{array}{l}\text { Correlação } \\
\text { de imagens: } \\
\text { Natural-50 } \\
\text { ciclos }\end{array}$ & $\begin{array}{l}\text { Coeficiente de correlação } \\
\text { linear de Pearson; } \\
\text { Progressão aritmética para } \\
\text { a total descaracterização e; } \\
\text { Tempo em anos. }\end{array}$ \\
\hline 75 & $\begin{array}{l}\text { Analise macroscópica; } \\
\text { inserção da câmara. }\end{array}$ & 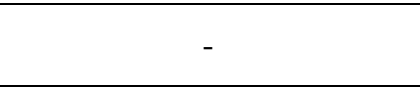 & - & - \\
\hline 100 & $\begin{array}{l}\text { Analise macroscópica; } \\
\text { Digitalização (TIFF, } R G B \\
\text { 24bits, } 600 \text { dpi); } \\
\text { Análise visual (lupa } \\
\text { binocular óptica). }\end{array}$ & $\begin{array}{c}\text { Sobreposição; Ajuste } \\
\text { rotação; } \\
\text { Recorte }(9 \times 14 \mathrm{~cm}) \\
\text { Conversão: } T I F F / J P E G \text { e } \\
R G B \text { 24bits/ Escala de cinza } \\
\text { 8bits. }\end{array}$ & $\begin{array}{l}\text { Correlação } \\
\text { de imagens: } \\
\text { Natural-100 } \\
\text { ciclos }\end{array}$ & $\begin{array}{l}\text { Coeficiente de correlação } \\
\text { linear de Pearson; } \\
\text { Progressão aritmética para } \\
\text { a total descaracterização e; } \\
\text { Tempo em anos. }\end{array}$ \\
\hline
\end{tabular}


A Etapa 1, laboratorial, é a fase de aquisição dos dados (imagens, observações, anotações e interpretações acerca da ausência ou do surgimento de peculiaridades em cada corpo de prova, amostra ou litotipo).

Nela foram utilizadas, além da câmara Fitoclima 300EDTU, uma câmera Nikon Coolpix P510, uma lupa binocular óptica Nikon SMZ645 e uma impressora multifuncional para digitalização Epson com resolução máxima de 600 dpi.

Ressalta-se que a descaracterização medida é a superficial e que as amostras não passaram por qualquer limpeza entre os intervalos de exposição, sendo que a imagem digitalizada após 100 ciclos representa o acúmulo das exposições (ciclos) anteriores.

$\mathrm{Na}$ Etapa 2, pré-processamento, a sobreposição das imagens foi feita para garantir que qualquer pixel tivesse as mesmas coordenadas $(\mathrm{X}, \mathrm{Y})$ tanto na imagem digitalizada ao natural quanto nas digitalizadas após os ciclos necessitando, em alguns casos, do ajuste de rotação para correção de seu posicionamento.

As imagens originais possuem dimensões de $10 \times 15 \mathrm{~cm}$ adquiridas em formato TIFF (Tagged Image File Format) no padrão de cor $R G B$ e em 24 bits, contudo, foram realizados cortes nas dimensões 9x14cm para evitar ruídos de borda. Foi também realizada a conversão para o formato JPEG (Joint Photographic Experts Group) $e$ depois para escala de cinza em 8bits possibilitando sua utilização no ImageJ.

A Etapa 3, consiste na correlação entre duas imagens e foi feita no software livre e de estrutura aberta ImageJ (NIH, 2014a), com o auxílio do plugin Image Correlator (NIH, 2014b) que compara um pixel em uma imagem ou raster com o pixel de mesma coordenada (Agora, $\mathrm{X}=$ Valor de $\mathrm{X}, \mathrm{Y}$ da imagem ao natural; $\mathrm{Y}=$ Valor de $\mathrm{X}$, Y imagem após os ciclos) na imagem a ser correlacionada, como na figura 3.

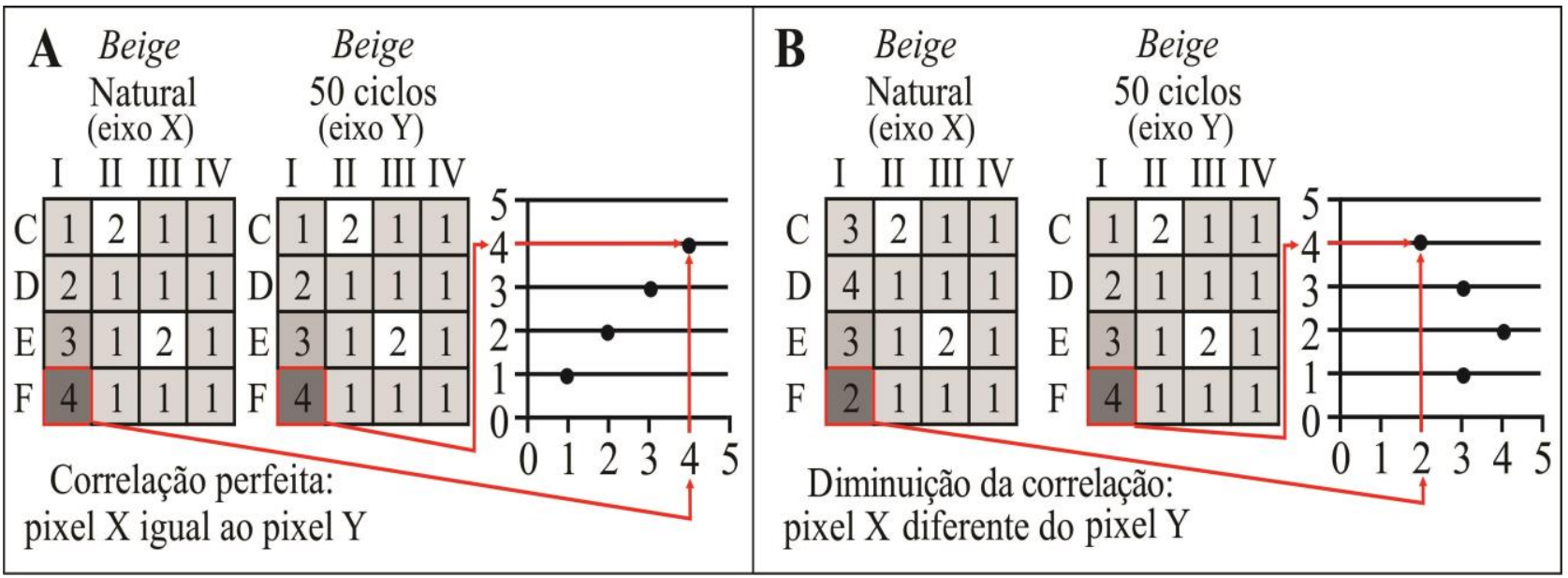

Figura 3 - Representação do método utilizado para correlacionar imagens.

Legenda: A) Exemplo de ausência de descaracterização; B) Exemplo de descaracterização; Eixos X e Y da imagem referem-se ao gráfico de correlação entre o valor do pixel na imagem Natural (X) e o valor do pixel na imagem 50 ciclos $(\mathrm{Y})$.

As imagens são então correlacionadas na seguinte ordem: Natural (0 ciclo) e 50 ciclos; Natural (0 ciclo) e 100 ciclos.

Sendo que a correlação entre Natural ( 0 ciclo) e Natural (0 ciclo) corresponderá sempre ao padrão de imutabilidade das imagens (correlação perfeita).

O Image $J$, na sequência, fornece uma planilha com os valores $\mathrm{X}$ e $\mathrm{Y}(\mathrm{X}=$ valor do pixel na digitalização ao natural e $\mathrm{Y}=$ valor do pixel na digitalização após os ciclos) para cada correlação. Estes valores são utilizados para calcular, no software Excel, o Coeficiente de Correlação Linear de Pearson $(r)$, de acordo com a equação 1 (Excel, 2013).

$$
\boldsymbol{r}=\frac{\sum(\boldsymbol{x}-\overline{\boldsymbol{x}})(\boldsymbol{y}-\overline{\boldsymbol{y}})}{\sqrt{\sum(\boldsymbol{x}-\overline{\boldsymbol{x}})^{2} \sum(\boldsymbol{y}-\bar{y})^{2}}} \quad r \in[-1,1] \quad \text { Eq. (1) }
$$

onde: $\boldsymbol{x}=$ valor do píxel na imagem ao natural; $\bar{x}=$ Média aritmética para os valores dos pixels na imagem ao natural; $\mathrm{y}=$ valor do pixel na imagem que se quer correlacionar; $\overline{\boldsymbol{y}}$ Média aritmética para os valores dos pixels na imagem que se quer correlacionar.

O valor de $\boldsymbol{r}$ é então calculado para cada corpo de prova, ou seja, 5 vezes para cada litotipo e 3 para cada correlação, totalizando 45 cálculos (15 para o Beige, 15 para o Gold e 15 para o Green). Para simplificar o resultado, foram calculadas as médias entre os cinco corpos de prova de cada litotipo e seus respectivos desvios padrões, 
diminuindo a quantidade de valores de $\boldsymbol{r}$ para 3 em cada correlação (total de 9 resultados).

As correlações foram identificadas de modo a representar a imagem ao natural e a imagem do ciclo que se deseja correlacionar, como: rO_O, correlação entre a imagem digitalizada ao natural e ela própria; r0_50, correlação entre a imagem ao natural e a imagem após 50 ciclos; r0_100, correlação entre a imagem ao natural e a imagem após 100 ciclos. A classificação do valor de $\boldsymbol{r}$ segue a tabela 4 e a figura 5, adaptadas de Souza (2008), Cohen (1988) e Dancey \& Reidy (2006).

Tabela 4 - Classificação relacionada ao Coeficiente de Correlação de Pearson.

\begin{tabular}{|c|c|c|}
\hline Coeficiente de Correlação Linear de Pearson $(r)$ & Correlação & Descaracterização da rocha \\
\hline $\mathbf{r}=\mathbf{1}$ & Perfeita Positiva & Nula \\
\hline $\mathbf{0 , 8} \leq \mathbf{r}<\mathbf{1}$ & Forte positiva & Fraca \\
\hline $0,5 \leq r<0,8$ & Moderada positiva & Moderada \\
\hline $0,1 \leq r<0,5$ & Fraca positiva & Considerável \\
\hline $0<r<0,1$ & Ínfima positiva & Forte \\
\hline $\mathbf{0}$ & Nula & Total descaracterização \\
\hline$-0,1<r<0$ & Ínfima negativa & Forte \\
\hline$-0,5<r \leq-0,1$ & Fraca negativa & Considerável \\
\hline$-0,8<r \leq-0,5$ & Moderada negativa & Moderada \\
\hline$-1<\mathbf{r} \leq-\mathbf{0 , 8}$ & Forte negativa & Fraca \\
\hline $\mathbf{r}=\mathbf{- 1}$ & Perfeita negativa & Nula \\
\hline
\end{tabular}

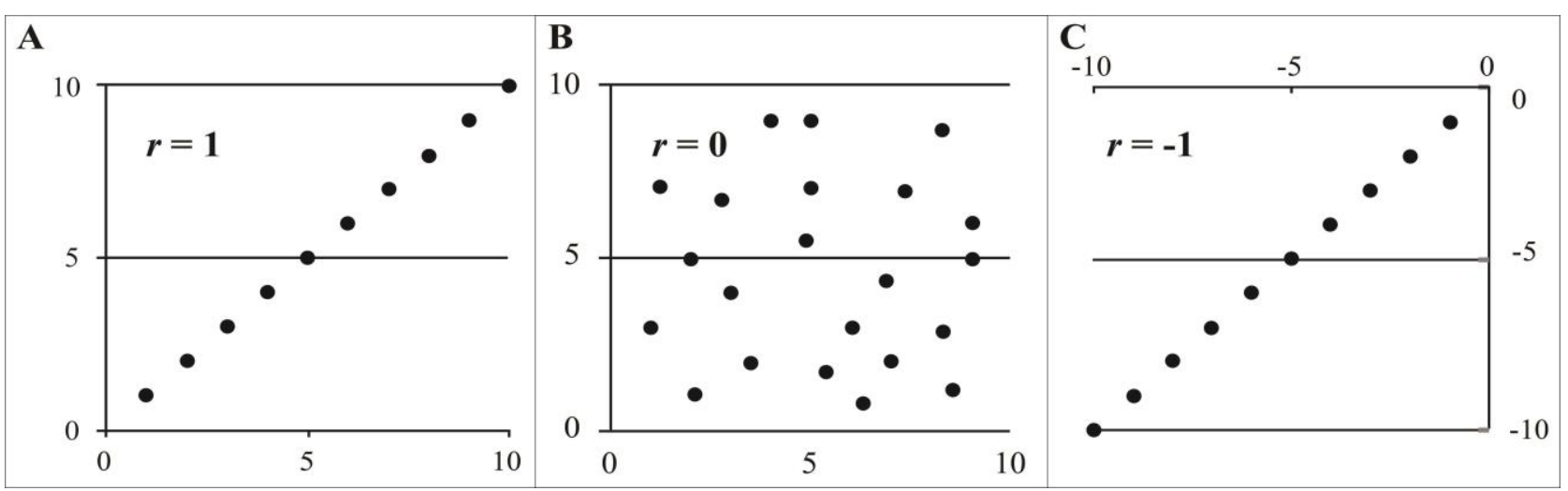

Figura 5 - Ilustração dos valores extremos de $\boldsymbol{r}$.

Legenda: A) Perfeita positiva/Descaracterização Nula; B) Correlação Nula/Total descaracterização; C) Perfeita negativa/Descaracterização Nula.

Com os valores de $\boldsymbol{r}$ calculados, o passo seguinte é determinar quando seu valor será igual a zero (0), levando em consideração os valores adquiridos com os cálculos ao longo das correlações realizadas.

Adotando que os valores de $\boldsymbol{r}$ ao longo das correlações se organizarão em progressão aritmética (P.A.), objetiva-se então encontrar a quantidade de ciclos que serão necessários para que a imagem digitalizada, após as exposições ao teste de envelhecimento acelerado, perca totalmente sua correlação com a imagem digitalizada da mesma ao natural.

Neste momento, com $\boldsymbol{r}$ igual a zero, a amostra (imagem) estará totalmente descaracterizada, não apresentando qualquer correlação com a original (Natural). Para chegar ao resultado ( $\boldsymbol{r}=$ $0)$ utiliza-se a equação do termo geral de uma Progressão Aritmética (equação 2). $a_{n}=a_{1}+(n-1) \cdot k \quad$ Eq. (2)

onde: $a_{n}=$ valor no enésimo termo; $a_{1}=1^{\circ}$ termo da P.A.; $n=$ número de termos da P.A. e; $k=$ razão da P.A.

Adotando que os valores das correlações $r 0 \_0$ terão valor igual a 1 , sempre e para quaisquer amostras, utilizaremos os valores de $\mathrm{rO}_{-} 50 \mathrm{e}$ r0_100 como termos iniciais da P.A., sendo r0_50 o $1^{\circ}$ termo e $r 0 \_100$ o $2^{\circ}$ termo $\boldsymbol{a}_{\boldsymbol{n}}$ será igual a zero (0) pois o que se quer encontrar é o tempo que a amostra levaria para chegar a este valor (total descaracterização), portanto o tempo será igual a quantidade de ciclos ou de termos $\boldsymbol{n}$. Invertendo os termos da equação 2 temos que:

$$
n=\left(\frac{a_{n}-a_{1}}{k}\right)+1 \quad \text { Eq. (3) }
$$

Cada ciclo equivale, como dito anteriormente, a um período de 13 horas de insolação. Considerando que só é possível que haja um ciclo 
desses ao longo de 1 dia (24 horas), dá-se que um ciclo dentro da câmara equivale a um dia fora dela (ao ar livre).

Logo, a cada 50 ciclos a câmara simula 50 dias de exposição ao ar livre em condições hipotéticas.

Para começar a calcular o tempo aproximado em anos $\boldsymbol{t}_{\boldsymbol{y}}$, é necessário multiplicar o número de termos da P.A. (n) pela quantidade de ciclos que cada termo representa $(50$ ciclos $=50$ dias $) \mathrm{e}$ dividir por 365 dias (1 ano) como pode ser visualizado na equação (4), onde $\boldsymbol{t}$ corresponde

\section{RESULTADOS E DISCUSSÃO}

Após a realização de todos os cálculos do valor de $\boldsymbol{r}$ com o uso da equação 1, no Excel, demonstram-se (tabela 5) os resultados para as correlações r0_50 e r0_100 ciclos.

Ao aplicar as equações 13,14 e 15 para as amostras temos:

\section{- Para o Butterfly Beige:}

Aplicando a equação 3:

- $1^{\circ}$ Termo $\left(\boldsymbol{a}_{\mathbf{1}}\right)=r 0 \_50=\mathbf{0 , 5 6}$

- $2^{\circ}$ Termo $\left(\boldsymbol{a}_{2}\right)=r 0 \_100=\mathbf{0 , 5 3}$

- $\operatorname{Razão}(\boldsymbol{k})=\left(2^{\circ}\right.$ termo $-1^{\circ}$ termo $)=\left(r 0 \_100\right.$ ao tempo em anos com concentração do gás em $25 \mathrm{ppm}$.

$$
\boldsymbol{t}=\frac{n \times 50 \text { dias }}{365 \text { dias }} \quad \text { Eq. (4) }
$$

Em seguida, considerando uma região com uma estação chuvosa bem definida ( 2 meses no verão, e. g.), com o uso da equação 5 saberemos quantos anos a amostra levará para chegar a total descaracterização $\left(\boldsymbol{t}_{\boldsymbol{y}}\right)$ com a concentração do gás em 25 ppm.

$$
\boldsymbol{t}_{\boldsymbol{y}}=\frac{t \times 12 \text { meses }}{2 \text { meses }} \quad \text { Eq. (5) }
$$

$\left.-r 0 \_50\right)=0,53-0,56=\mathbf{- 0 , 0 3}$

- Valor do enésimo termo $\left(\boldsymbol{a}_{\boldsymbol{n}}\right)=\mathbf{0}$ (total descaracterização)

- Número de termos da P.A.

$$
(\boldsymbol{n})=\left(\frac{a_{n}-a_{1}}{k}\right)+1=\left(\frac{\mathbf{0}-\mathbf{0 , 5 6}}{-\mathbf{0 , 0 3}}\right)+1=\mathbf{1 9 , 5 0}
$$

Como só existem termos de números inteiros em uma P.A. adota-se o termo que é consecutivo ao valor do termo de $\boldsymbol{n}$ calculado, nesse caso o $20^{\circ}$.

Logo, a P.A. terá a configuração presente na tabela 6.

Tabela 5 - Resultados de $\boldsymbol{r}$ para as imagens das amostras testadas.

\begin{tabular}{c|c|c|c|c}
\hline \multirow{2}{*}{ Litotipo } & \multicolumn{3}{|c}{ Coeficientes de correlação linear de Pearson $(\boldsymbol{r})$} \\
\cline { 2 - 5 } & \multicolumn{2}{|c}{ r0_50 } & \multicolumn{2}{c}{ r0_100 } \\
\cline { 2 - 5 } & Média & Desvio Padrão & Média & Desvio Padrão \\
\hline Butterfly Beige & 0,56 & 0,05 & 0,53 & 0,02 \\
\hline Butterfly Gold & 0,69 & 0,07 & 0,44 & 0,08 \\
\hline Butterfly Green & 0,37 & 0,06 & 0,27 & 0,06 \\
\hline
\end{tabular}

Tabela 6 - Progressão aritmética para o Butterfly Beige.

\begin{tabular}{c|c|c|c|c|c|c|c|c|c|c}
\hline Termos & $\mathbf{1}^{\mathbf{o}}$ & $\mathbf{2}^{\mathbf{o}}$ & $\mathbf{3}^{\mathbf{o}}$ & $\mathbf{4}^{\mathbf{o}}$ & $\mathbf{5}^{\mathbf{o}}$ & $\mathbf{6}^{\mathbf{o}}$ & $\mathbf{7}^{\mathbf{o}}$ & $\mathbf{8}^{\mathbf{o}}$ & $\mathbf{9}^{\mathbf{o}}$ & $\mathbf{1 0}^{\mathbf{o}}$ \\
\hline Ciclos (dias) & 50 & 100 & 150 & 200 & 250 & 300 & 350 & 400 & 450 & 500 \\
\hline Valor de $\boldsymbol{r}$ & 0,56 & 0,53 & 0,50 & 0,47 & 0,44 & 0,41 & 0,38 & 0,35 & 0,32 & 0,29 \\
\hline Termos & $\mathbf{1 1}^{\mathbf{o}}$ & $\mathbf{1 2}^{\mathbf{o}}$ & $\mathbf{1 3}^{\mathbf{o}}$ & $\mathbf{1 4}^{\mathbf{o}}$ & $\mathbf{1 5}^{\mathbf{o}}$ & $\mathbf{1 6}^{\mathbf{o}}$ & $\mathbf{1 7}^{\mathbf{o}}$ & $\mathbf{1 8}^{\mathbf{o}}$ & $\mathbf{1 9}^{\mathbf{o}}$ & $\mathbf{2 0}^{\mathbf{o}}$ \\
\hline Ciclos (dias) & 550 & 600 & 650 & 700 & 750 & 800 & 850 & 900 & 950 & 1000 \\
\hline Valor de $\boldsymbol{r}$ & 0,26 & 0,23 & 0,20 & 0,17 & 0,14 & 0,11 & 0,08 & 0,05 & 0,02 & $\mathbf{- 0 , 0 1}$ \\
\hline
\end{tabular}

Como o valor de $\boldsymbol{r}$ igual à zero (0) está entre os termos $19^{\circ}$ e $20^{\circ}$, efetua-se então os cálculos do tempo aproximado, em anos, usando o $20^{\circ}$ termo na equação 4 .
Ao aplicar a equação 5, convertemos o tempo $\boldsymbol{t}$ (com concentração do gás em 25ppm) considerando a estação chuvosa, calculando o valor de $\boldsymbol{t}_{\boldsymbol{y}}$.

$$
t_{y}=\frac{t \times 12 \text { meses }}{3 \text { meses }}=\frac{2,67 \times 12}{2}=16,03 \text { anos. }
$$


O tempo que será gasto pela amostra para que fique totalmente descaracterizada $(r=0)$ é de 16,03 anos, mostrando uma descaracterização moderada (figura 6) com $r 0 \_50=0,56$ e $r 0 \_100=0,53$ ficando dentro do intervalo $0,5 \leq \mathrm{r}<0,8$ no tempo que a amostra ficou dentro da câmara (100 ciclos).

- Para o Butterfly Gold:

Aplicando a equação 3:

- $1^{\circ}$ Termo $\left(\boldsymbol{a}_{1}\right)=r 0 \_50=\mathbf{0 , 6 9}$
- $2^{\circ}$ Termo $\left(\boldsymbol{a}_{2}\right)=r 0 \_100=\mathbf{0 , 4 4}$

- Razão $(\boldsymbol{k})=\left(2^{\circ}\right.$ termo $-1^{\circ}$ termo $)=\left(r 0 \_100-\right.$ $\left.r 0 \_50\right)=0,44-0,69=\mathbf{- 0 , 2 5}$

- Valor do enésimo termo $\left(\boldsymbol{a}_{\boldsymbol{n}}\right)=\mathbf{0}$

Número de termos da P.A.

$$
(n)=\left(\frac{a_{n}-a_{1}}{k}\right)+1=\left(\frac{0-0,69}{-0,25}\right)+1=3,74
$$

Como só existem termos de números inteiros em uma P.A. adota-se o termo consecutivo ao do valor de $\boldsymbol{n}$ calculado, nesse caso o $4^{\circ}$. Logo, a P.A. terá a configuração presente na tabela 7 .

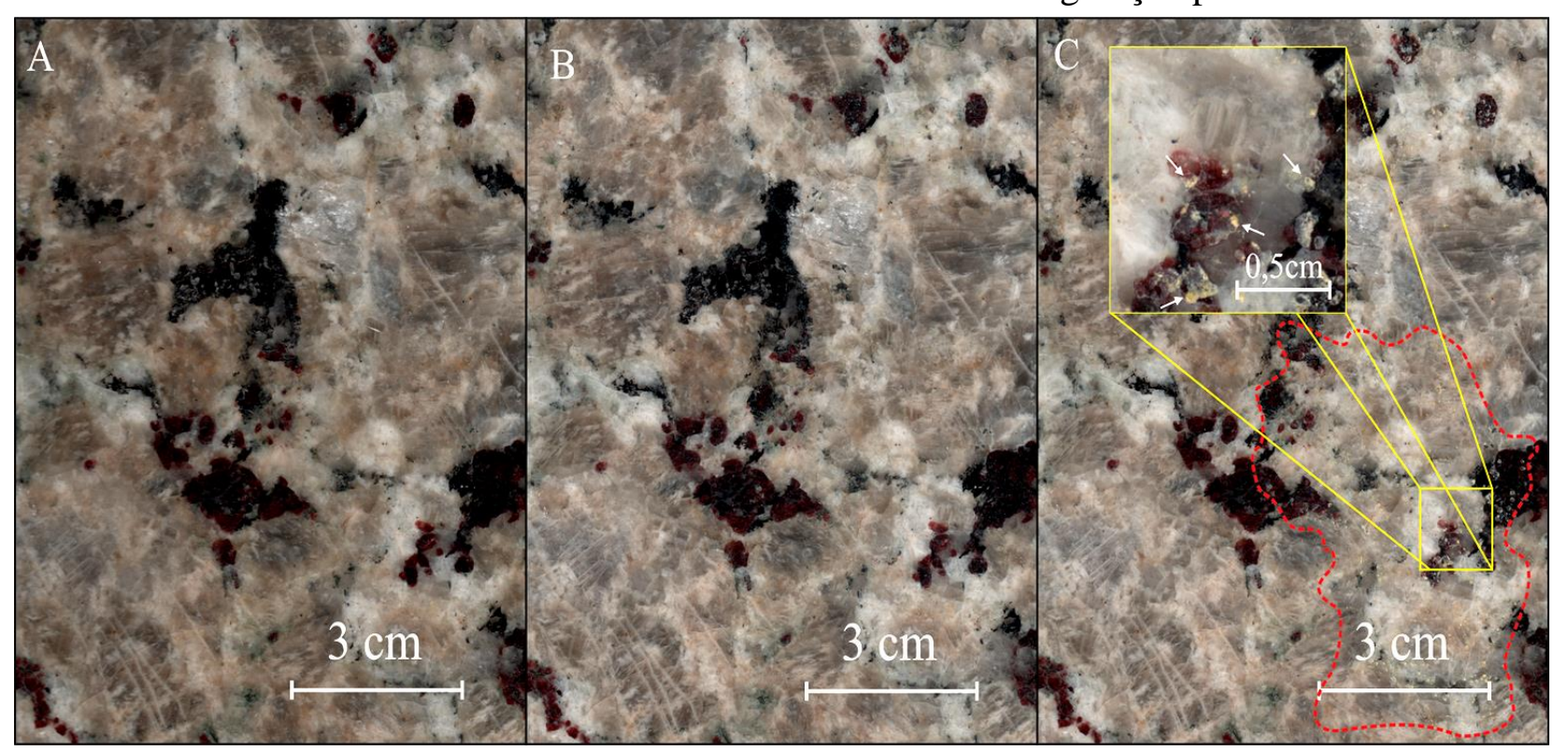

Figura 6 - Exemplo de parte de um corpo de prova do Butterfly Beige utilizado no ensaio.

Legenda: A) Ao Natural (0 ciclo); B) Após 50 ciclos; C) Após 100 ciclos. As setas brancas no destaque em amarelo indicam o material cristalizado, provavelmente sulfatos e/ou argilominerais. Área atacada delimitada em vermelho.

Tabela 7 - Progressão aritmética para o Butterfly Gold.

\begin{tabular}{c|c|c|c|c}
\hline Termos & $\mathbf{1}^{\mathbf{o}}$ & $\mathbf{2}^{\mathbf{o}}$ & $\mathbf{3}^{\mathbf{o}}$ & $\mathbf{4}^{\mathbf{o}}$ \\
\hline $\begin{array}{c}\text { Ciclos } \\
\text { (dias) }\end{array}$ & 50 & 100 & 150 & 200 \\
\hline $\begin{array}{c}\text { Valor } \\
\text { de } \boldsymbol{r}\end{array}$ & 0,69 & 0,44 & 0,19 & $\mathbf{0 , 0 6}$ \\
\hline
\end{tabular}

Como o valor de $\boldsymbol{r}$ igual à zero (0) está entre os termos $3^{\circ}$ e $4^{\circ}$, efetua-se então os cálculos do tempo aproximado, em anos, a partir do $4^{\circ}$ termo usando a equação 4 .

$\boldsymbol{t}=\frac{n \times 50 \text { dias }}{365 \text { dias }}=\frac{4 \times 50}{365}=\frac{200}{365}=0,51$ ano.

Ao aplicar a equação 5, convertemos o tempo $\boldsymbol{t}$ (com concentração do gás em 25ppm) considerando a estação chuvosa, calculando o valor de $\boldsymbol{t}_{\boldsymbol{y}}$.

$\boldsymbol{t}_{\boldsymbol{y}}=\frac{t \times 12 \text { meses }}{3 \text { meses }}=\frac{0,51 \times 12}{2}=3,91$ anos.

O tempo gasto pela amostra para ficar totalmente descaracterizada $(r=0)$ será de 3,91 anos e já puderam ser visualizados no ensaio os primeiros efeitos da descaracterização nos corpos de prova (Figura 7).

Para o Butterfly Gold, a classificação quanto a descaracterização para 100 ciclos já apresenta valores $\left(r 0 \_50=0,69 ; r 0 \_100=0,44\right)$ que vão da classificação moderada $(0,5 \leq r<0,8)$ a considerável $(0,1 \leq r<0,5)$ mostrando, apartir destes valores, sua maior propensão à descaracterização estética superficial em relação ao Butterfly Beige e ao Butterfly Green.

\section{- Para o Butterfly Green:}

Aplicando a equação 3:

- $1^{\circ}$ Termo $\left(\boldsymbol{a}_{\mathbf{1}}\right)=r 0 \_50=\mathbf{0 , 3 7}$

- $2^{\circ}$ Termo $\left(\boldsymbol{a}_{2}\right)=r 0 \_100=\mathbf{0 , 2 7}$

- $\operatorname{Razão}(\boldsymbol{k})=\left(2^{\circ}\right.$ termo $-1^{\circ}$ termo $)=\left(r 0 \_100\right.$

$\left.-r 0 \_50\right)=0,27-0,37=\mathbf{- 0 , 1 0}$

- Valor do enésimo termo $\left(\boldsymbol{a}_{\boldsymbol{n}}\right)=\mathbf{0}$

- Número de termos da P.A. 


$$
(n)=\frac{a_{n}-a_{1}}{k}+1=\frac{0-0,37}{-0,10}+1=4,76
$$

Logo, a P.A. terá a configuração presente na tabela 8 .

Tabela 8 - Progressão aritmética para o Butterfly Green.

\begin{tabular}{l|l|l|l|l|l}
\hline Termos & $\mathbf{1}^{\mathbf{o}}$ & $\mathbf{2}^{\mathbf{o}}$ & $\mathbf{3}^{\mathbf{o}}$ & $\mathbf{4}^{\mathbf{o}}$ & $\mathbf{5}^{\mathbf{o}}$ \\
\hline Ciclos (dias) & 50 & 100 & 150 & 200 & 250 \\
\hline Valor de $\boldsymbol{r}$ & 0,37 & 0,27 & 0,17 & 0,07 & $-0,02$ \\
\hline
\end{tabular}

Como o valor de $\boldsymbol{r}$ igual à zero (0) está entre o termo $4^{\circ}$ e o $5^{\circ}$, efetua-se então os cálculos do tempo aproximado, em anos, a partir do $5^{\circ}$ termo usando a equação 4. $t=\frac{n \times 50 \text { dias }}{365 \text { dias }}=\frac{5 \times 50}{365}=\frac{250}{365}=0,65$ anos.

Ao aplicar a equação 5, convertemos o tempo $\boldsymbol{t}$ (com concentração do gás em $25 \mathrm{ppm}$ ) considerando a estação chuvosa, calculando-se o valor de $\boldsymbol{t}_{\boldsymbol{y}}$.

$t_{y}=\frac{t \times 12 \text { meses }}{3 \text { meses }}=\frac{0,65 \times 12}{2}=3,91$ anos.

O tempo, em anos, gasto pela amostra para ficar totalmente descaracterizada $(r=0)$ será de 3,91 e já é possível verificar os efeitos (Figuras $8 \mathrm{~A}, \mathrm{~B}, \mathrm{C})$ da descaracterização nos primeiros ciclos, apresentam-se descaracterizadas.

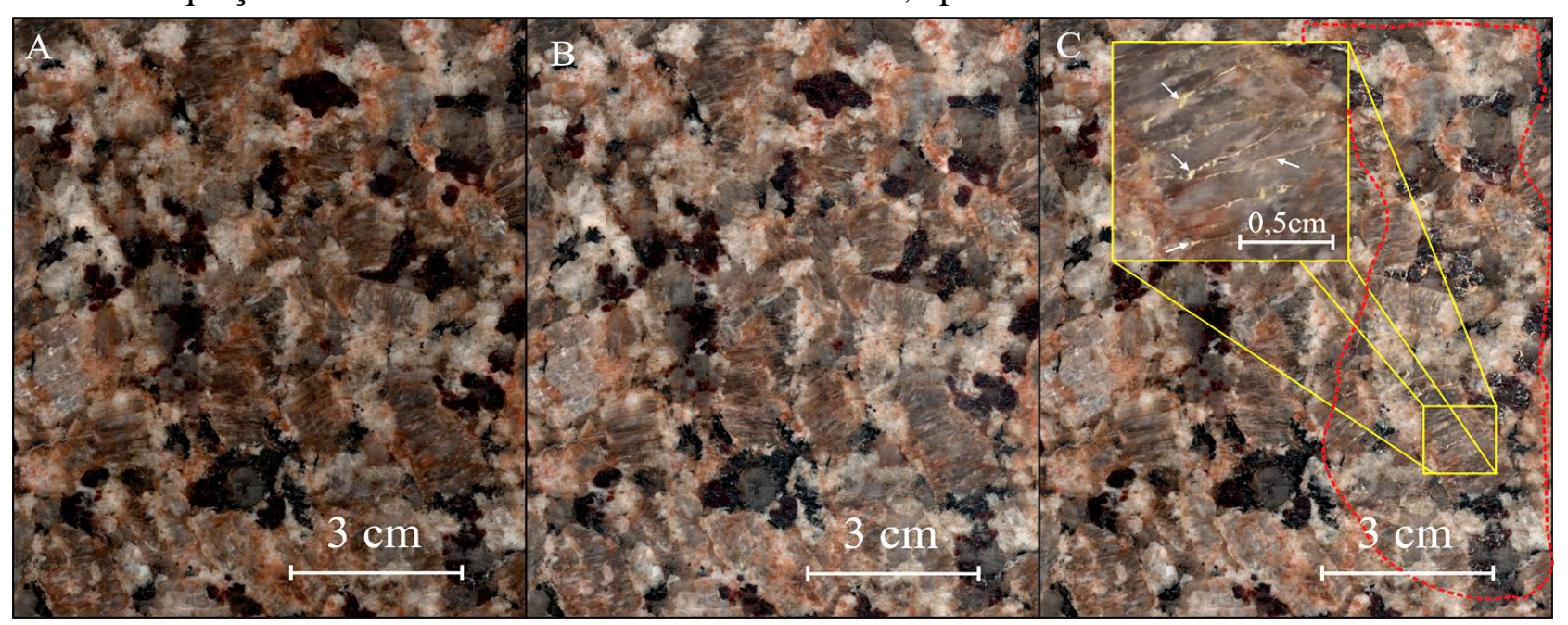

Figura 7 - Exemplo de parte de corpo de prova do Butterfly Gold utilizado no ensaio.

Legenda: A) Ao Natural (0 ciclo); B) Após 50 ciclos; C) Após 100 ciclos: observa-se materiais, provavelmente sulfatos (destaque em amarelo) e/ou argilominerais cristalizados nos planos de clivagem de alguns cristais de microclínio e sobre biotitas, plagioclásios e granadas (área delimitada de vermelho).

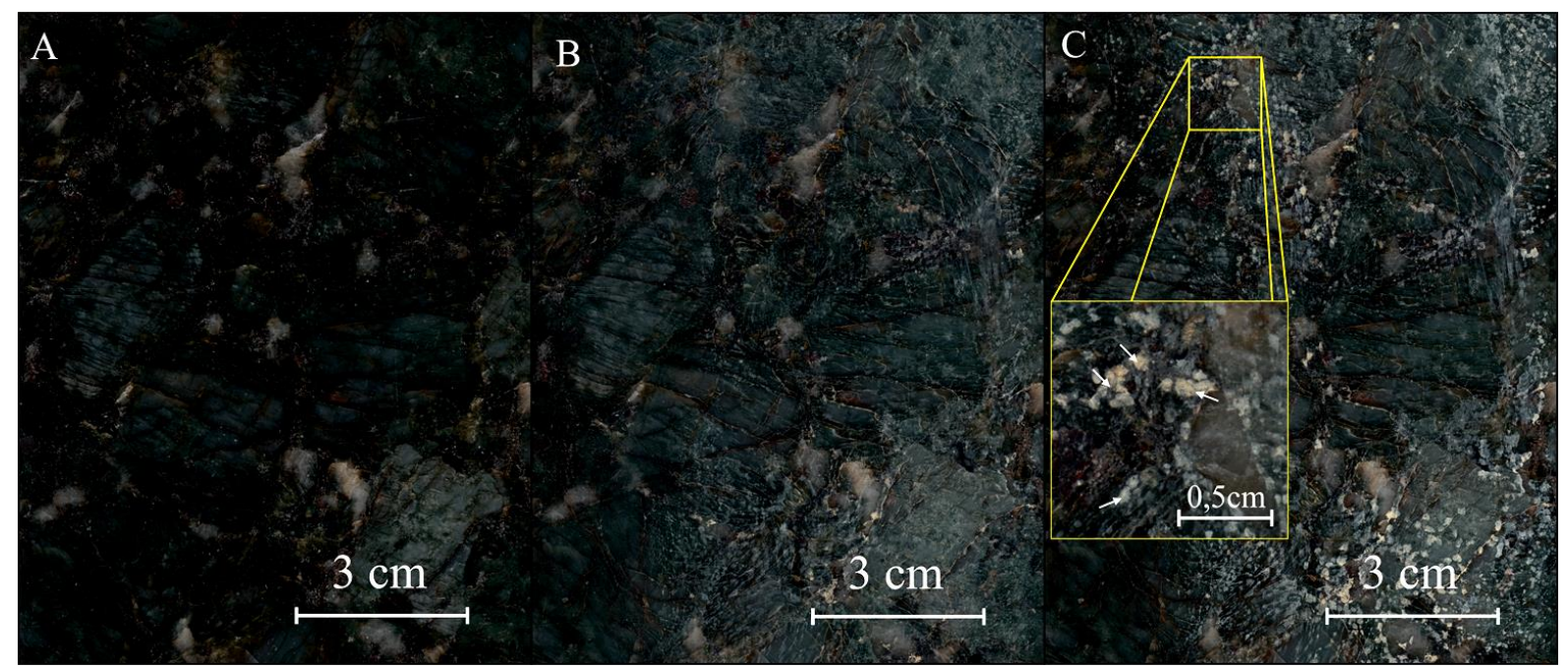

Figura 8 - Exemplo de corpo de prova do Butterfly Green utilizado no ensaio.

Legenda: A) Ao Natural (0 ciclo); B) Após 50 ciclos; C) Após 100 ciclos. Observa-se em B e C, material cristalizado, provavelmente sulfatos (destaque em amarelo) e/ou argilominerais, sobre praticamente toda a superfície da amostra. Tais feições foram identificadas já na análise macroscópica dos 25 ciclos.

De forma sumária, na tabela 9 e na figura 9 ornamentais Butterfly Beige, Butterfly Green e estão representados os tempos que seriam Butterfly Gold para a total descaracterização teoricamente gastos pelas amostras das rochas estética superficial. 
Tabela 9. Tempo aproximado necessário para a total descaracterização superficial.

\begin{tabular}{c|c}
\hline Amostra & Tempo aproximado em anos $\left(\boldsymbol{t}_{\boldsymbol{y}}\right)$ \\
\hline Butterfly Beige & 16,03 \\
\hline Butterfly Gold & 3,08 \\
\hline Butterfly Green & 3,91 \\
\hline
\end{tabular}

A figura $10 \mathrm{~A}$ mostra o ataque químico sofrido pelo Butterfly Beige, sobretudo imposto às granadas. A amostra Butterfly Gold mostra, no entanto, que os efeitos do ataque vão além dos ocorridos sobre a granada (figura 10B), ocorrendo também sobre a biotita (Figura 10C). Quanto ao Butterfly Green, as interações mineral/ácido sulfúrico são mais intensas, com maiores quantidades e dimensões dos materiais cristalizados (figura 10D) sobretudo nos planos de clivagens dos cristais de microclínio (Figuras 10E, F).

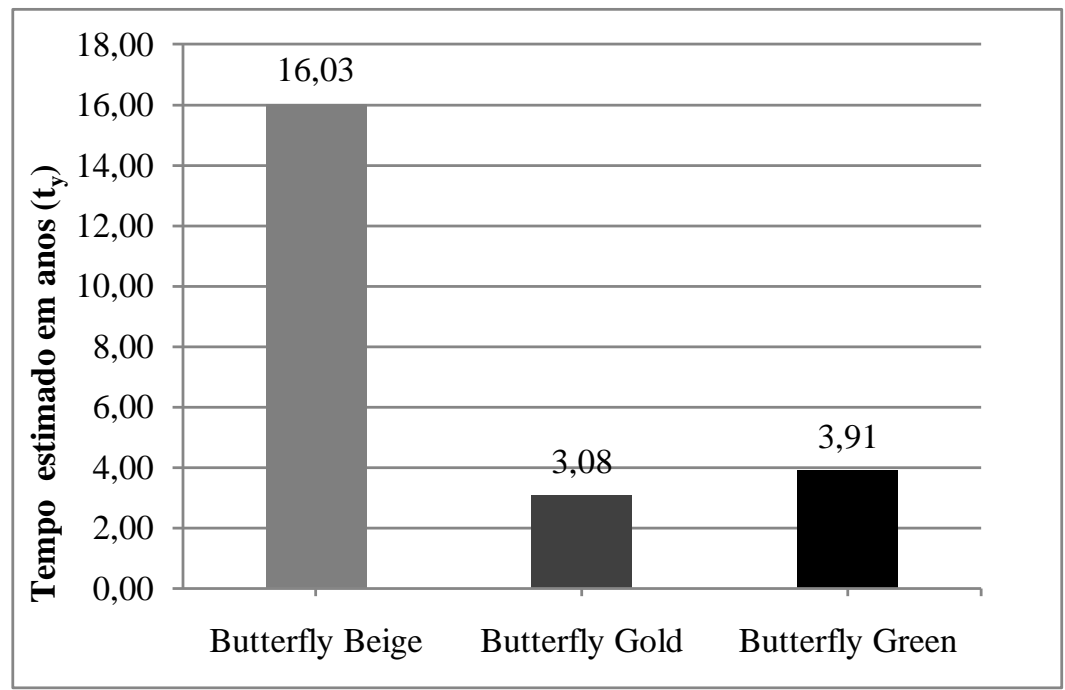

Figura 9. Tempo aproximado necessário à total descaracterização estética superficial.

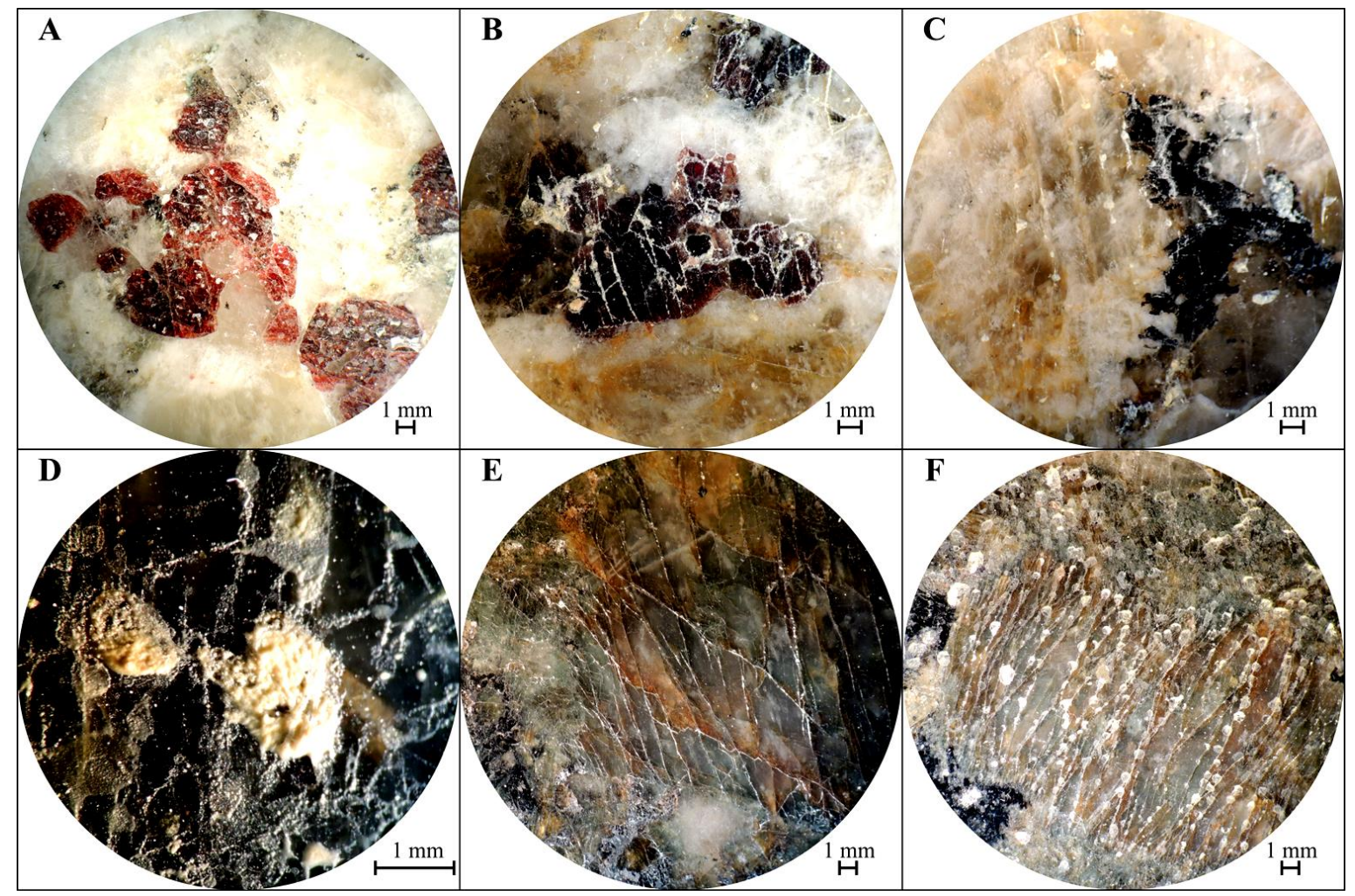

Figura 10 - Fotografias obtidas com o auxílio de uma câmera e uma lupa óptica binocular.

Legenda: A) Butterfly Beige; B e C) Butterfly Gold e; D, E e F) Butterfly Green.

A análise sob a lupa óptica binocular mostrou (reação) entre os minerais constituintes e, que, não só houve a cristalização de sais sobre a principalmente, o ácido sulfúrico $\left(\mathrm{H}_{2} \mathrm{SO}_{4}\right)$ amostra como também ocorreu a interação formando cristais em planos de clivagens, em 
fraturas de diversos minerais e sobre sua superfície descaracterizada.

Os desvios padrão referentes às médias de $\boldsymbol{r}$ para os corpos de prova dos tipos litológicos (Tabela 6) mostram que não há uma grande dispersão desses valores, com todos os valores de desvio padrão abaixo de 0,1 como, por exemplo, nas correlações r0_50 (Beige 0,05; Gold 0,07; Green 0,06), indicando que os corpos de prova se comportam de maneira praticamente uniforme dentro de cada intervalo de ciclos e dentro de cada amostra analisada, sendo que para as correlações $r 0 \_100$ os desvios padrão são ainda menores (Beige 0,02; Gold 0,08; Green 0,06).

\section{CONCLUSÕES}

O método de previsão da descaracterização superficial pode ser uma ferramenta útil para se ter uma noção do comportamento das superfícies frente às solicitações impostas pelas intempéries. Sabe-se que na natureza as interações químicas e físicas geralmente não ocorrem de forma linear como proposto pelo método de previsão devendo, portanto, tomar uma série de cuidados ao utilizar a ferramenta que, por tratar separadamente os efeitos causados pela exposição à atmosfera saturada em $\mathrm{SO}_{2}$, não leva em consideração os outros gases presentes na atmosfera e que deterioram de forma significativa as rochas como, por exemplo, o gás carbônico que por sua vez forma o ácido carbônico $\left(\mathrm{H}_{2} \mathrm{CO}_{3}\right)$.

A tonalidade das amostras influencia na avaliação visual do que é material neo-cristalizado e o que é rocha de fato, já que a alteração ou o material cristalizado na superfície possui coloração clara, como a do Butterfly Beige, por exemplo. Contudo, esse problema não existe na correlação entre as imagens pois ela é sempre feita entre a imagem do corpo de prova exposto ao teste e a sua imagem original pelo software.

A alteração entre os minerais ocorre de forma sequencial atingindo cristais de granada, biotita, hiperstênio, microclínio e plagioclásios respectivamente.

A ação do ácido sulfúrico ocorre sobretudo em descontinuidades estruturais e planos de fraqueza como, por exemplo, as clivagens dos cristais de microclínio.

Classificando em ordem crescente o tempo necessário à descaracterização a amostra Butterfly Gold é a rocha mais susceptível (3,08 anos), seguida do Butterfly $G$ (3,91 anos) e do Butterfly Beige (16,03 anos).

Lembrando que a descaracterização é super- ficial, o fato de a imagem se descaracterizar não implica necessariamente em alteração ou comprometimento estrutural ou físico-mecânico da rocha.

Uma vez que as amostras não passaram por qualquer limpeza entre os ciclos, não foi possível analisar o efeito do ataque químico sob a camada cristalizada na superfície das amostras. Sugere-se então que na realização deste teste sejam adotados, sistematicamente nos intervalos entre os ciclos, os procedimentos de:

- secagem e posterior digitalização da superfície da amostra assim que ela sair da câmara;

- raspagem (se houver) do material cristalizado e/ou acumulado, sua pesagem, identificação e análise química. $\mathrm{O}$ objetivo é a identificar a ocorrência da alteração, sua intensidade e a seguir determinar o tipo de composto formado a partir das reações químicas decorrentes do ensaio;

- na sequência, sugere-se a lavagem da superfície com água destilada para remoção do material remanescente da raspagem, a secagem e, em seguida, a digitalização da superfície atacada (limpa).

A concentração do gás na câmara $(25 \mathrm{ppm})$ foi superelevada propositalmente para acelerar o processo de deterioração. É importante lembrar que a câmara simula as condições climáticas em fluxo praticamente contínuo necessitando o pesquisador, para as interpretações, considerar a concentração de $\mathrm{SO}_{2}$ na atmosfera, a duração das estações chuvosas, a incidência de chuvas ácidas e suas intensidades ao longo de um ano nos diferentes territórios.

As previsões aqui realizadas não são impeditivos para aplicação destes materiais em ambientes externos nem tampouco internos, pois procedimentos usuais de limpeza podem ser perfeitamente aplicados para conservação dos mesmos.

\section{AGRADECIMENTOS}

À Guidoni Mineração Ltda pelo auxílio e cessão das amostras, à CAPES proc.: 3030/13-0, ao CNPq Proc.: 141706/2012-0 pelas bolsas e ao Centro de Petrologia e Geoquímica do Instituto Superior Técnico de Lisboa, Portugal, pela infraestrutura e pessoal disponibilizados à pesquisa. 


\section{REFERÊNCIAS}

AIRES-BARROS, L.; MAURÍCIO, A.M.; FIGUEIREDO, C.A Definição de um índice de alterabilidade de rochas por aplicação de métodos de análise de imagem baseados na morfologia matemática binária. Geociências, Revista Universidade de Aveiro, v. 5, fasc. 1/2. p. 95-102. 1991a.

AIRES-BARROS, L.; MAURÍCIO, A.M.; FIGUEIREDO, C.A. Aplicação do perfilômetro de linhas à alteração e alterabilidade de rochas ornamentais carbonatadas. Publ. Mus. Lab. Mineral Geol., Universidade de Coimbra, Memórias e Notícias, n. 122, p. 67-80, 1991b.

AIRES-BARROS, L.; MAURÍCIO, A.M.; FIGUEIREDO, C.A. Experimental correlations between alterability indexes obtained by laboratorial ageing tests and by image analysis. In La Détérioration des matériaux de construction. In: INTERNATIONAL SYMPOSIUM LA ROCHELLE. P., La Rochelle - France, 1991. Atas...La Rochelle. 199-208, 1991c.

ALKIMIN, F.F.; PEDROSA-SOARES, A.C.; NOCE, C.M.; CRUZ, S.C.P. Sobre a evolução tectônica do Orógeno AraçuaíCongo Ocidental. Geonomos, v. 15, n. 1, p. 24-43, 2007.

ALMEIDA, F.F.M. Geologia do Continente Sul Americano: Evolução da Obra de Fernando Marques de Almeida. In: MANTESSO-NETO, V.; BARTORELI, A.; CELSO, D.R.C.; BRITO-NEVES, B.B. (Coords), 211p., 2004.

BOLONINI, T.M. Estudo das Aplicações das Variedades de Um Quartzo Sienito Com Hiperstênio, Como Rochas Ornamentais, Com Auxílio da Caracterização Tecnológica e das Análises de Cor e Imagem. Rio Claro, 2015, 134 p. Tese de (Doutorado). Instituto de Geociências e Ciências ExatasUniversidade Estadual Paulista

BOLONINI, T M. \& GODOY, A.M. Caracterização Tecnológica dos Quartzo Sienitos com Hiperstênio Butterfly Beige e Butterfly Green. Geociências, v. 36, n. 3, p. 442-458, 2017.

BOLONINI, T.M.; GODOY, A.M.; BOLONINI, L.C.A.S.; SILVEIRA, L.L.L.; SANTOS, E. Análise de cor em imagens digitais e análise de brilho para rochas ornamentais submetidas ao ataque químico. In: SIMPÓSIO DE ROCHAS ORNAMENTAIS DO NORDESTE IX, João Pessoa, 2016a. Anais... João Pessoa: CETEM, 2016 ${ }^{\mathrm{a}}$

BOLONINI, T.M.; GODOY, A.M.; BOLONINI, L.C.A.S.; SILVEIRA, L.L.L.; SANTOS, E. Uso da correlação entre imagens na classificação da descaracterização superficial de rochas ornamentais submetidas ao ataque químico. In: SIMPÓSIO DE ROCHAS ORNAMENTAIS DO NORDESTE IX. João Pessoa, 2016b. Anais... João Pessoa: CETEM, 2016b.

BOLONINI, T.M.; GODOY, A.M.; FIGUEIREDO, C.A.M.; MAURÍCIO, A.; PEREIRA, M.F.; CLEMENTE, I.M.; SILVA, F.D.O. Análises de cor e Imagem das Rochas Ornamentais Butterfly Beige, Butterfly Gold e Butterfly Green expostas a altas temperaturas. Geociências, v. 36, n. 4, p. 703-716, 2017.

COHEN, J. Statistical power analysis for the behavioral sciences. Hillsdale, NJ, Erlbaum, 1988.

CPRM. Serviço Geológico do Brasil. Geologia da Folha de Mantena - SE.24-Y-A-VI - Programa Geologia do Brasil nota explicativa da folha Mantena. Escala 1:100.000, 2007.

DANCEY, C. \& REIDY, J. Estatística Sem Matemática para Psicologia: Usando SPSS para Windows. Porto Alegre, Artmed, 2006.

EXCEL. Microsoft office - Excel. Função Pearson. Disp. em: https://support.office.com/pt-br/article/PEARSON-Fun\%C3\% A7\%C3\%A3o-PEARSON-0c3e30fc-e5af-49c4-808a-3ef66e $034 \mathrm{c} 18$ ?ui $=\mathrm{pt}-\mathrm{BR} \& \mathrm{rs}=\mathrm{pt}-\mathrm{BR} \& \mathrm{ad}=\mathrm{BR}$.

FIGUEIREDO, P.; FIGUEIREDO, C.A.M; AIRES-BARROS, L.; FLAMBÓ, A. Contribuição para o estudo cromático das rochas da capela do Palácio da Bemposta. Proelium. Revista da Academia Militar. VI série, n. 1, p. 168-178, 2004.

FIGUEIREDO, C.A.M.; FIGUEIREDO, P.; AIRES-BARROS, L.; PINA, P.; RAMOS, V. Texture analysis of images taken from artificially aged Stones: a statistical and structural approach. In: Restoration of Buildings and Monuments. An international Journal, v 11, n. 4, p. 235-245, 2005.

GOKAY, M.K. \& GUNDOGDU, I.B. Color identification of some Turkish marbles. Construction and Building Materials. v. 22, p. 1342-1349, 2004.

MARSHAK, S.; ALKIMI, F.F.; WHITTINGTON, A.; PEDROSA-SOARES, A.C. Extensional collapse in the Neoproterozoic Araçuaí orogen, eastern Brazil: a setting for reactivation of asymmetric crenulation cleavage. Journal of Structural Geology, v. 28, p. 129-147, 2006

MARTINS, V.T.S.; TEIXEIRA, W.; NOCE, C.M.; PEDROSASOARES, A.C. Sr and Nd Characteristics of Brasiliano/PanAfrican Granitoid Plutons of the Araçuaí Orogen, Southeastern Brazil: Tectonic Implications. Gondwana Research, v. 7, n. 1, p. 75-89, 2004.

MCGRAW, R. Condensation Nuclei Production from Sulfur Dioxide Photo-oxidation In Air. Journal of. Physical Chemistry, v. 86, p. 2750-2752, 1982.

MOTOKI, A.; VARGAS, T.; ZUCCO, L.L.; NEVES, J.L.P.: CARIO, F.D.; MOTOKI, K.F. Captura direta de imagens macroscópicas de rochas via scanner. Mineração e Metalurgia, v. 552, p. 25-30, 1999.

MOTOKI, A.; ZUCCO, L.L.; SICHEL, S.E.; AIRES, J.R.; PETRAKIS, G.H. Desenvolvimento da técnica para especificação de cores e a nova nomenclatura para classificação de rochas ornamentais com base nas cores medidas. São Paulo, UNESP, Geociências, v. 25, n. 4, 403-415p., 2006a.

MOTOKI, A.; PETRAKIS, G.H.; SICHEL, S.E.; AIRES, J.R. Método para analises modais semi-automáticas de fenocristais grandes com o auxílio da técnica da especificação quantitativa de cores. In: CONGRESSO BRASILEIRO DE GEOLOGIA, 43, 2006, Aracajú. Resumo Expandido...Aracajú: Sociedade Brasileira de Geologia, CD-ROM. 2006b.

NOCE, C.M.; PEDROSA-SOARES, A.C.; SILVA, L.C.; ARMSTRONG, R.; PIUZANA, D. Evolution of polycyclic basement complexes in the Araçuaí Orogen, based on U-Pb SHRIMP data: Implications for Brazil- Africa links in Paleoproterozoic time. Precambrian Research, v. 159, p. 60-78, 2007. PEDROSA-SOARES, A.C.; NOCE, C.M.; VIDAL, P.H.; MONTEIRO, R.L.B.P.; LEONARDOS, O.H. Toward a new tectonic model for the Late Proterozoic Araçuaí (SE Brazil) West Congolian (SW Africa) Belt. Journal of South American Science, v. 6, n. 1/2, p. 33-47, 1992.

PEDROSA-SOARES, A.C.; NOCE, C.M.; WIEDEMANN, C.M.; PINTO, C.P. The Araçuaí-West-Congo Orogen in Brazil: an overview of a confined orogen formed during Gondwanaland assembly. Precambrian Research, v. 110, p. 307-323, 2001.

PEDROSA-SOARES, A.C.; CASTAÑEDA, C.; QUEIROGA, C.; GRADIM, C.; BELÉM, J.; RONCATO, J.; NOVO, T.; DIAS, P.; GRADIM, D.; MEDEIROS, S.; JACOBSOHN, T.; BABINSKI, M.; VIEIRA, V. Magmatismo e tectônica do Orógeno Araçuaí no extremo Leste de Minas e Norte do Espírito Santo $\left(18^{\circ}-19^{\circ} \mathrm{S}, 41^{\circ}-40^{\circ} 30^{\prime} \mathrm{W}\right)$. Geonomos, v. $14, \mathrm{n}$. 1/2, p. $97-111,2006$

PEDROSA-SOARES, A.C.; NOCE, C.M.; ALKIMIM, F.F.; SILVA, L.C.; BABINSKI, M., CORDANI, U.; CASTAÑEDA, C. Orógeno Araçuaí: Síntese do Conhecimento 30 anos após Almeida 1977. Geonomos, v. 15, n. 1, p. 1-16, 2007.

RONCATO JÚNIOR, J.G. As Suítes Graníticas Tipo-S do norte do Espírito Santo na região das Folhas Ecoporanga, Mantena, Montanha e Nova Venécia. Belo Horizonte, 2009, 103p. Dissertação (Mestrado em Geociências) - Instituto de Geociências, Universidade Federal de Minas Gerais.

SETHI, D.S. Photo-Oxidation of Sulfur Dioxide. Journal of the Air Pollution Control Association, v. 21, n. 7, p. 418-420, 1971. 
SOUZA, A. Coeficiente de Correlação de Pearson. Mestrado em Gestão (MBA). Departamento de Matemática da Universidade dos Açores. Portugal (2008). Disp. em: http://www.aurea.uac.pt/pdf_MBA/coef_correl_Pearson.pdf. TORQUATO, M.F.B.; TORQUATO, J.R.F.; FIGUEIREDO, C.A.M.; NOGUEIRA NETO, J.A.N. Estudo dos granitos cearenses "Vermelho Filomena, Meruoca Clássico e Verde Ceará" por análise digital de imagem em câmara com atmosfera satura em $\mathrm{SO}_{2}$. Geonomos, v. 16, n. 2, p. 51-52, 2008.
VAZQUEZ, M.A.; GALÁN, E.; GUERRERO, M.A.; ORTIZ, P. Digital image processing of weathered stone caused by efflorescences: A tool for mapping and evaluation of stone decay. Construction and Building Materials, v. 25, p. 1603 1611, 2011.

Submetido em 14 de março de 2019 Aceito em 18 de setembro de 2019 